\title{
PERANCANGAN NEW MEDIA BERBASIS AUGMENTED REALITY UNTUK MENDUKUNG KEGIATAN PROMOSI IKADO GUNA MENJANGKAU CALON MAHASISWA
}

\author{
Briantito Adiwena ${ }^{1 *}$, Angga Hendrawan ${ }^{2}$, Mixzy Indrajaya ${ }^{3}$ \\ Institut Informatika Indonesia, Surabaya ${ }^{1^{*}}$ \\ briantito@ikado.ac.id
}

\begin{abstract}
Abstrak
Terbatasnya jarak dan waktu, seringkali membuat para calon mahasiswa terbatas untuk mengakses informasi mengenai IKADO, dengan dirancangnya media Augmented Reality ini, maka diharapkan informasi gedung dan fasilitas IKADO dapat diakses oleh para calon mahasiswa dan orang tua setiap saat. Metode pengumpulan data yang digunakan dalam perancangan ini menggunakan pendekatan kualitatif. Pengumpulan data mengenai indentitas IKADO, ukuran gedung dan fasilitas IKADO. Metode perancangan new media ini dilakukan dengan mengikuti beberapa metode yang telah dilakukan oleh perancang serupa dalam judul "penggunaan AR untuk proses pembuatan batik tulis", dan melakukan penyesuaian perancangan sesuai dengan identitas dan ukuran gedung dan fasilitas IKADO. Perancangan ini menghasilkan Media baru Augmented Reality berupa tampilan tiga dimensi gedung dan fasilitas IKADO. Media ini sebagai sarana informasi yg unik dan efektif tentang fasilitas IKADO, yang diharapkan agar mampu memberikan pengalaman baru khususnya dalam hal promosi yang belum banyak diterapkan oleh beberapa kampus lainnya, sehingga hal ini dapat menjadi solusi yang baik untuk menarik ketertarikan calon mahasiswa dan orang tua. Perancangan Media pendukung diharapkan mampu menjadi media pelengkap yang secara fungsional dapat menunjang media utama.
\end{abstract}

Kata kunci: new media, virtual reality, augmented realiy, interaktif

\begin{abstract}
The limited of distance and time, often makes prospective students are limited to accessing information about IKADO, with the design of Augmented Reality media, designer hoped that information on IKADO buildings and facilities can be accessed by prospective students and parents at any time. The data collection method used in this design uses a qualitative approach, collecting data regarding IKADO identity, IKADO building size and facilities. This new media design method is carried out by following several methods that have been carried out by similar designers under the title "AR for the use of the batik-making process", and making design adjustments according to the identity and size of IKADO buildings and facilities. This design
\end{abstract}


creates a new Augmented Reality Media in the form of a threedimensional view of IKADO buildings and facilities. This media is a unique and effective to explain information about IKADO facilities, which is expected to be able to provide new experiences, especially in terms of promotions that have not been widely applied by several other campuses, so that this can be a good solution to attract the interest of prospective students and parents. The design of supporting media is expected to be a complementary media which functionally can support the main media.

Key words: new media, augmented reality, virtual reality, interactive.

\section{PENDAHULUAN}

Setiap tahunnya, Perguruan Tinggi melakukan upaya untuk menjangkau calon mahasiswa mahasiswi baru. Indonesia, hingga tahun 2019 telah memiliki 4.621 Perguruan Tinggi (ristekdikti,2019) masing-masing Perguruan Tinggi memiliki tujuan yang sama yaitu menjangkau lebih banyak mahasiswa dengan berpartisipasi dalam berbagai acara pameran Pendidikan. Persaingan yang dilakukan berbagai macam Perguruan Tinggi memunculkan banyak strategi promosi baru dan kreatif salah satunya yaitu penggunaan teknologi Augmented Reality.

Institut Informatika Indonesia (IKADO), merupakan salah satu Perguruan Tinggi Swasta di Surabaya yang berfokus pada bidang Desain dan Informatika. IKADO juga memiliki tim PMB (Penerimaan Mahasiswa Baru) yang bertugas untuk mengelola aktivitas penerimaan mahasiswa baru. Tim PMB IKADO, telah melakukan berbagai usaha untuk menjelaskan bagaimana gedung dan fasilitas yang ada di IKADO baik melalui media promosi berbentuk media cetak seperti brosur, leaflet dan x banner maupun media digital berupa video profile kampus. Masalah serupa seperti para calon mahasiswa yang semula ingin mengunjungi dan melihat secara langsung gedung IKADO, menjadi mengurungkan niatnya karena terkendala jarak dan waktu, hal ini sangat disayangkan karena dapat menghambat calon mahasiswa untuk melakukan pendaftaran.

Salah satu solusi yang dapat digunakan untuk menyelesaikan masalah tersebut adalah, perancangan media yang dapat menampilkan simulasi fisik dari bentuk gedung IKADO serta fasilitas didalamnya. Dengan demikian, media 
tersebut dapat membantu tim PMB dalam menjelaskan dan menyampaikan informasi kepada para calon mahasiswa.

New Media berbasis Augmented Reality akan dirancang untuk digunakan sebagai simulasi bentuk 3Dimensi dari gedung dan fasilitas IKADO sehingga informasi yang ada, dapat diakses secara langsung oleh para calon mahasiswa. Teknologi AR dipilih karena mampu mensimulasikan bentukan 3dimensi dan dapat berinteraksi dengan para calon mahasiswa maupun menyampaikan informasi secara efektif. Diharapkan dengan penggunaan media AR ini, para calon mahasiswa dapat merasakan pengalaman berdasarkan situasi gedung dan fasilitas IKADO yang nyata.

\section{KAJIAN TEORI}

Institut Informatika Indonesia (IKADO) Surabaya menerima Ijin Pendirian dan Ijin Operasional melalui Surat Keputusan Menteri Pendidikan Nasional Republik Indonesia No. 11/D/O/2003, tertanggal 31 Januari 2003 untuk 6 Program Studi yaitu S1- Desain Komunikasi Visual, S1- Desain Produk, S1- Teknik Informatika, S1- Teknik Komputer, S1- Sistem Informasi, D3- Manajemen Informatika.

Promosi adalah perkenalan dalam rangka memajukan usaha dagang. Promosi tidak hanya untuk memajukan usaha dagang, namun juga perlu adanya peran Perusahaan untuk berinteraksi dan berkomunikasi dengan target konsumen. Proses ini disebut dengan komunikasi pemasaran terpadu atau Integrated Marketing Communication (IMC), yang didalamnya terdapat proses interaksi dan berbagai kegiatan pemasaran yang lain.

Pameran adalah bentuk kegiatan dalam promosi yang pada umumnya, pameran bertujuan untuk mempresentasikan suatu produk maupun jasa kepada masyarakat. Pengertian pameran menurut Evelina Lidia (2005: 4), Pameran merupakan event masyarakat yang diselenggarakan oleh suatu organisasi independen dan terbuka untuk umum. Pameran Pendidikan merupakan sarana, dimana informasi pendukung untuk menentukan minat ilmu tertentu dapat di akses dengan baik karena banyak sekolah maupun universitas yang turut hadir dalam acara tersebut. 
Multimedia berasal dari kata multi dan media. Multi yang berarti banyak dan media yang berarti perantara. Menurut McComick (1996), multimedia adalah gabungan dari beberapa unsur yaitu suara, gambar dan teks. Menurut Robin dan Linda (2001), multimedia adalah alat yang dapat menciptakan presentasi yang dinamis dan interaktif yang mengkombinasikan teks, grafik, animasi, audio dan video.

Augmented Reality (AR), adalah teknologi yang menggabungkan benda maya dua dimensi dan tiga dimensi kedalam sebuah lingkungan nyata tiga dimensi lalu memproyeksikan benda-benda maya tersebut dalam waktu nyata. (Muntahanah, Toyib dan Ansyori, 2017: 81).

Blender adalah software 3D pada komputer bersifat open source dan gratis. Blender digunakan untuk membuat berbagai proyek animasi, efek visual dan game engine. Blender memiliki berbagai fitur yang mudah digunakan seperti permodelan 3D, penciptaan tekstur, perancangan gerakan animasi dan berbagai simulasi ilmiah dengan tujuan memunculkan efek visual.

Unity adalah software game engine yang digunakan untuk merancang permainan 3dimensi dimana objek yang dibutuhkan akan disusun dan diberikan kode dengan Bahasa computer seperti $\mathrm{C} / \mathrm{C}++$ atau javascript sehingga dapat menjadi suatu keutuhan yang dapat dimainkan oleh pengguna. Pada proyek ini, Perancang hanya menggunakan fitur unity engine sebagai penyusun objek-objek 3D, penyusunan pencahayaan dan perancangan material tanpa melibatkan penggunaan proses coding.

Vuforia adalah aplikasi Augmented Reality yang diperuntukkan untuk gawai dimana aplikasi ini menggunakan kemampuan komputer dalam mengumpulkan data sehingga dapat mengenali dan mengikuti sebuah objek target atau marker yang berupa planar 2D.

\section{METODE PENELITIAN}

Analisis data yang digunakan dalam perancangan ini menggunakan pendekatan kualitatif. Subjek penelitian yaitu siswa siswi kelas 12 di Surabaya. Pengumpulan data dilakukan dengan cara melakukan wawancara kepada Rektor IKADO dan tim PMB IKADO dan melakukan pengumpulan data pada gedung dan 
fasilitas IKADO yang akan dirancang. Selain melakukan wawancara, juga dilakukan penelitian dan pengumpulan data melalui observasi. Observasi bertujuan untuk mempelajari aspek-aspek yang digunakan sebagai komparator.

\section{HASIL DAN PEMBAHASAN}

Perancangan new media berbasis Augmented Reality ini ditujukan untuk calon mahasiswa mahasiswi IKADO atau siswa siswi kelas 12 di Surabaya yang sedang mencari universitas dibidang Informatika dan Desain. New media ini diharapkan dapat memberikan pengalaman yang nyata dan efektif dalam menyampaikan informasi mengenai IKADO serta mendukung promosi yang dilakukan tim PMB IKADO agar lebih menarik perhatian.

\section{Media Utama}

Media utama ini digunakan agar para calon mahasiswa dan orang tua dapat menerima informasi mengenai IKADO secara efektif. Media utama berbentuk buku image target yang berisi tentang fasilitas IKADO dicetak dalam ukuran A4 dengan hardcover dan aplikasi Augmented Reality yang bisa diunduh oleh calon mahasiswa melalui gawainya masing-masing. Aplikasi ini digunakan untuk membaca image target yang terdapat pada buku. Buku image target didesain dengan menerapkan bentuk dan warna dari identitas IKADO, sehingga desain buku didominasi dengan warna dasar putih dengan kombinasi warna biru dan oranye. Foto dalam buku diambil dengan posisi eye level untuk memberikan prespektif sebenarnya dengan pencahayaan alami dan buatan (pencahayaan ruangan).

Tabel 1. Spesifikasi Media Utama

\begin{tabular}{|l|l|l|l|}
\hline No & \multicolumn{1}{|c|}{ Jenis } & \multicolumn{1}{c|}{ Ukuran } & \multicolumn{1}{c|}{ Keterangan } \\
\hline 1 & $\begin{array}{l}\text { Buku image target } \\
\text { gedung dan } \\
\text { fasilitas IKADO }\end{array}$ & $29.7 \mathrm{~cm} \times 21 \mathrm{~cm}$ & $\begin{array}{l}\text { Buku ukuran A4, dijilid } \\
\text { hardcover }\end{array}$ \\
\hline 2 & $\begin{array}{l}\text { Aplikasi } \\
\text { Augmented } \\
\text { Reality }\end{array}$ & $198 \mathrm{MB}$ & $\begin{array}{l}\text { Aplikasi ini digunakan untuk } \\
\text { membaca image target dari } \\
\text { buku gedung dan fasilitas. } \\
\text { Aplikasi ini akan diunggah di } \\
\text { Google Play Store }\end{array}$ \\
\hline
\end{tabular}

Sumber: Penulis 


\section{Proses Digital}

Proses terbentuknya 3D AR dimulai dengan pengambilan gambar dan pengukuran langsung ruangan-ruangan yang akan dijadikan objek penelitian yang meliputi luas ruangan, furnitur, perangkat elektronik dan detail benda yang terdapat dari masing-masing ruangan. Dari data tersebut kemudian dilakukan modeling 3D dengan menggunakan software Blender kemudian dilanjutkan dengan membawa file 3D tersebut ke software Unity 3D dan Vuforia untuk proses pembuatan Augmented Reality.

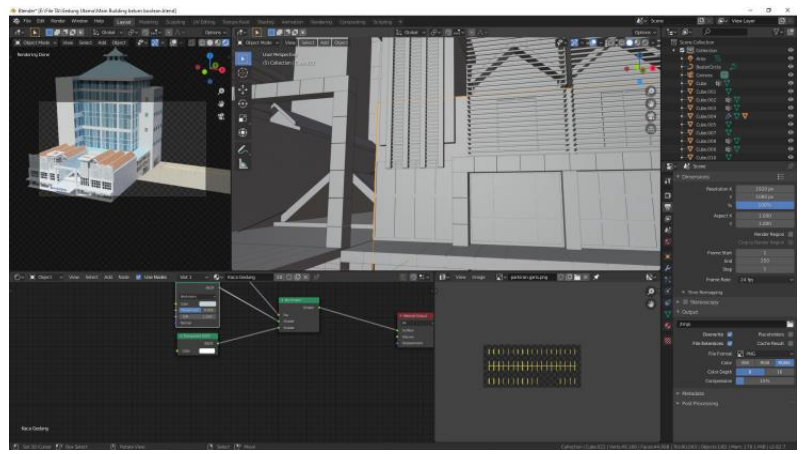

Gambar 1. Proses Digital Gedung Utama

Sumber: Penulis

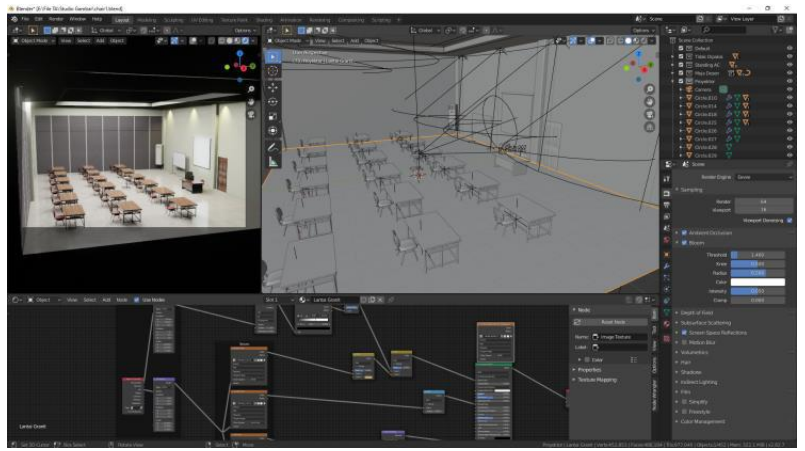

Gambar 2. Proses Digital Fasilitas Kampus

Sumber: Penulis

\section{Desain Akhir}

Pada bagian cover bagian depan menampilkan informasi judul yang dikomposisikan dengan desain layout geometris, modern dan minimalis dengan mengadaptasi dari bentuk logo IKADO. Sedangkan pada bagian cover belakang menampilkan logo IKADO beserta informasi alamat kampus, menggunakan desain 
yang didominasi warna biru dengan memperhatikan keseimbangan komposisi warna antara cover depan dengan belakang.

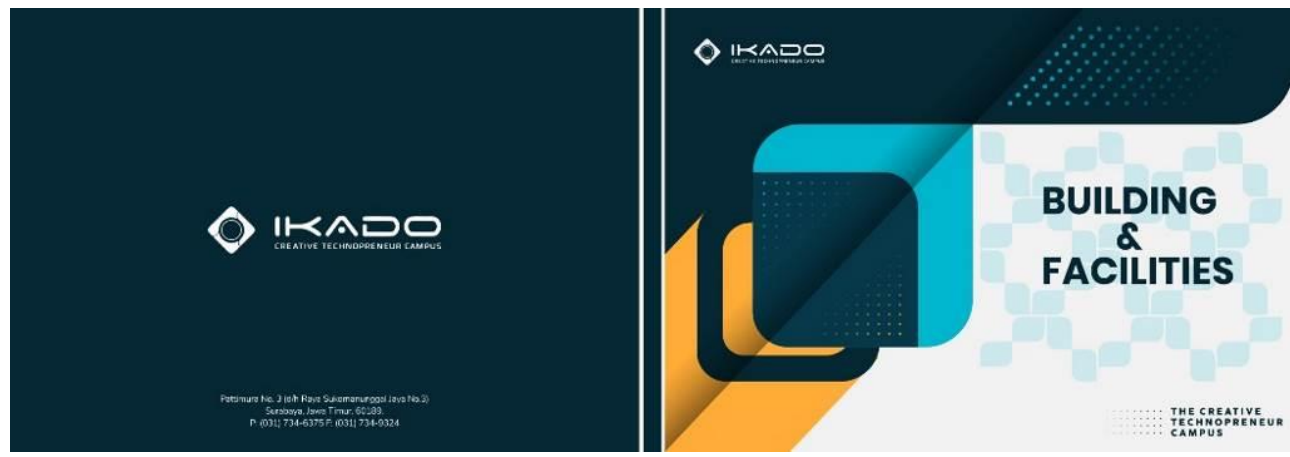

Gambar 3. Desain Cover Belakang dan Depan

Sumber: Penulis

Pada halaman utama berisi tentang profil IKADO sebagai pendahuluan, bertujuan untuk memberikan informasi terkait jurusan dan fasilitas-fasilitas yang terdapat di IKADO. Menggunakan latar berwarna biru dengan kombinasi typeface Sans Serif Poppins yang memiliki karakter solid dan berwarna putih agar mudah dibaca.

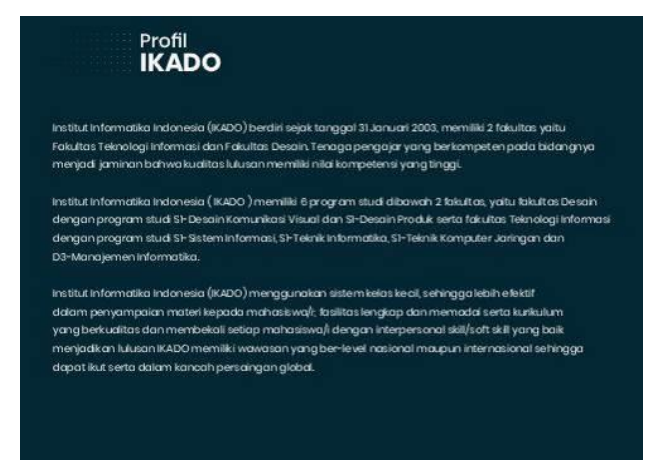

\section{Gambar 4. Desain Halaman Pendahuluan}

Sumber: Penulis

Sedangkan pada halaman-halaman berikutnya berisi tentang informasi dan foto tentang gedung dan fasilitas-fasilitas yang terdapat di IKADO. Pada halaman genap (sisi kiri) berisikan informasi tertulis dan beberapa foto penunjang dan pada halaman ganjil (sisi kanan) berisikan image target dan barcode yang dapat dipindai dengan aplikasi AR yang sudah didownload. 


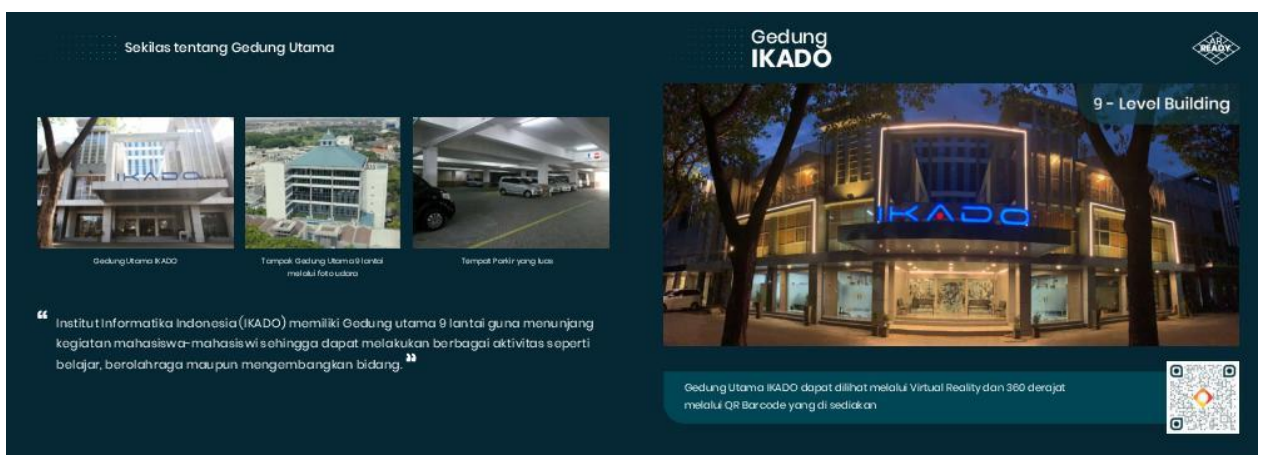

Gambar 5. Desain Halaman Gedung IKADO

Sumber: Penulis

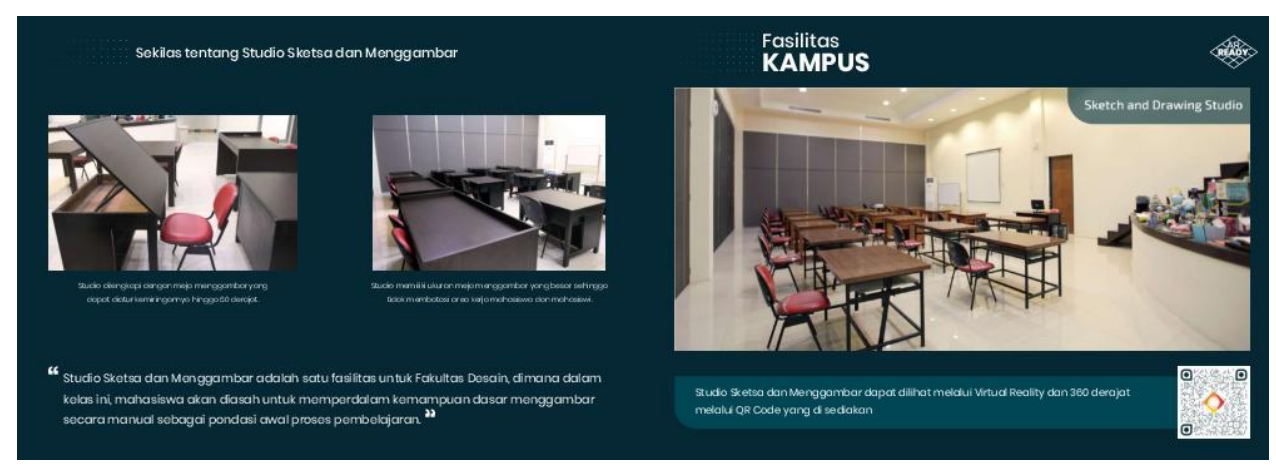

Gambar 6. Desain Halaman Fasilitas Kampus

Sumber: Penulis

Hasil pindai image target akan memunculkan tampilan 3D di layar gawai dan dapat digeser untuk mendapatkan prespesktif yang berbeda dari tiap sudut. Dengan menggunakan tampilan 3D maka calon mahasiswa akan mendapatkan pengalaman langsung untuk berada di fasilitas ruang-ruang yang ada di IKADO dan diharapkan dapat menarik minat calon mahasiswa untuk melanjutkan pendidikan tingginya ke IKADO.

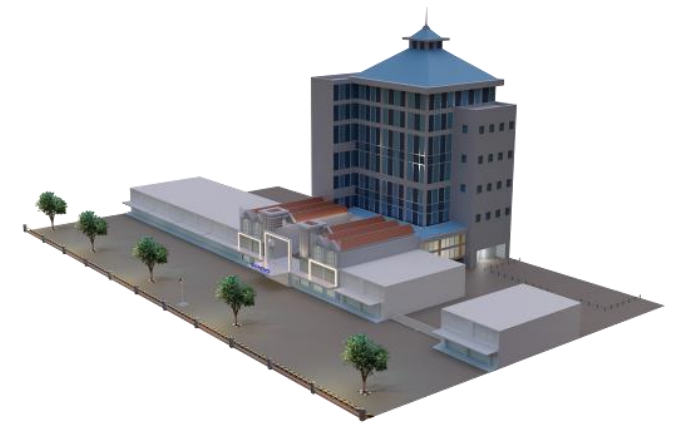

Gambar 7. Hasil Render 3D AR Gedung Utama

Sumber: Penulis 


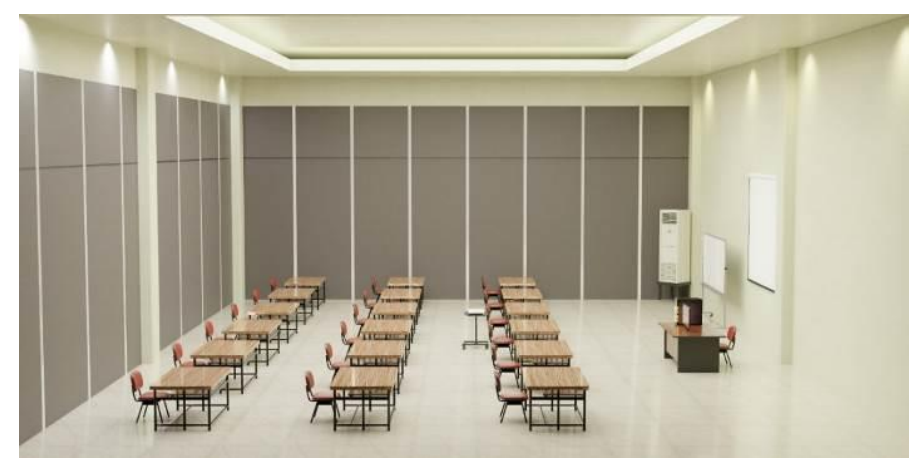

Gambar 8. Hasil Render 3D AR Fasilitas Kampus

Sumber: Penulis

\section{Media Pendukung}

Media pendukung digunakan sebagai penjelas informasi pada media utama, sehingga informasi dapat diterima secara optimal oleh calon mahasiswa. Media pedukung ini diterapkan dalam pameran pendidikan yang diselenggarakan didalam atau diluar ruangan. Media pendukung didesain juga dengan menerapkan bentuk dan warna dari identitas IKADO, sehingga desain media pendukung didominasi dengan style minimalis dengan kombinasi warna biru dan oranye.

Tabel 2. Spesifikasi Media Pendukung

\begin{tabular}{|l|l|l|l|}
\hline No & \multicolumn{1}{|c|}{ Jenis } & \multicolumn{1}{c|}{ Ukuran } & \multicolumn{1}{c|}{ Keterangan } \\
\hline 1 & Brosur A4 & $29.7 \mathrm{~cm} \times 21 \mathrm{~cm}$ & $\begin{array}{l}\text { Brosur ini digunakan sebagai } \\
\text { informasi singkat dan QR- } \\
\text { code untuk mengakses video } \\
\text { 360 derajat dan virtual reality } \\
\text { IKADO. }\end{array}$ \\
\hline 2 & Roll Banner & $200 \mathrm{~cm} \times 80 \mathrm{~cm}$ & $\begin{array}{l}\text { Roll Banner ini akan } \\
\text { diletakkan di booth pameran } \\
\text { Pendidikan dengan tujuan } \\
\text { untuk menarik minat calon } \\
\text { mahasiswa dan orang tua } \\
\text { terhadap informasi IKADO. }\end{array}$ \\
\hline 3 & Image 360 derajat & $144 \mathrm{p}-4 \mathrm{~K}$ resolution & $\begin{array}{l}\text { Image 360 derajat gedung } \\
\text { dan fasilitas IKADO yang di } \\
\text { unggah pada situs } \\
\text { facebook.com }\end{array}$ \\
\hline 4 & Video 360 derajat & $144 \mathrm{p}-4 \mathrm{~K}$ resolution & $\begin{array}{l}\text { Video 360 derajat gedung } \\
\text { dan fasilitas IKADO yang di } \\
\text { unggah pada situs }\end{array}$ \\
\hline
\end{tabular}




\begin{tabular}{|l|l|l|l|}
\hline No & \multicolumn{1}{|c|}{ Jenis } & \multicolumn{1}{|c|}{ Ukuran } & \multicolumn{1}{|c|}{ Keterangan } \\
\hline 5 & Virtual Reality & $144 \mathrm{p}-4 \mathrm{~K}$ resolution & $\begin{array}{l}\text { youtube.com } \\
\text { Image 360 derajat gedung } \\
\text { dan fasilitas IKADO yang di } \\
\text { unggah pada situs } \\
\text { youtube.com }\end{array}$ \\
\hline 6 & $\begin{array}{l}\text { Layout Booth Pameran } \\
\text { dengan 1 arah masuk }\end{array}$ & $2,5 \mathrm{~m} \times 3 \mathrm{~m} \times 3 \mathrm{~m}$ & $\begin{array}{l}\text { Layout ini digunakan sebagai } \\
\text { acuan agar penempatan } \\
\text { seluruh media dapat optimal. }\end{array}$ \\
\hline 7 & $\begin{array}{l}\text { Layout Booth Pameran } \\
\text { dengan 2 arah masuk. }\end{array}$ & $2,5 \mathrm{~m} \times 3 \mathrm{~m} \mathrm{x} \mathrm{3m}$ & $\begin{array}{l}\text { Layout ini digunakan sebagai } \\
\text { acuan agar penempatan } \\
\text { seluruh media dapat optimal. }\end{array}$ \\
\hline
\end{tabular}

Sumber: Penulis

\section{Alur Kerja Media}

Berikut ini adalah alur yang akan dilalui oleh calon mahasiswa sebagai target konsumen dalam perancangan media Augmented Reality:

1. Pengunjung booth pameran IKADO, akan mengunduh aplikasi AR melalui QR-code pada roll banner.

2. Pengunjung akan menjalankan aplikasi AR IKADO dan masuk ke menu utama.

3. Akan ada 3 menu utama yaitu Start Augmented Reality, Info Aplikasi dan Credit

4. Start Augmented Reality berfungsi untuk melihat bentukan 3dimensi dari gedung dan fasilitas IKADO dengan cara mengarahkan kamera pada image target yang berada di buku gedung dan fasilitas yang telah disediakan.

5. Setelah selesai melihat AR, pengguna dapat menekan tombol kembali sehingga akan diarahkan menuju menu utama

6. Info Aplikasi berfungsi untuk memberikan latar belakang dari perancangan media AR

7. Credit berfungsi untuk menampilkan profil singkat tentang perancang aplikasi dan perancang 3dimensi AR

8. Info Aplikasi dan Credit masing-masing memiliki tombol kembali sehingga selalu dapat kembali ke tampilan menu utama. 


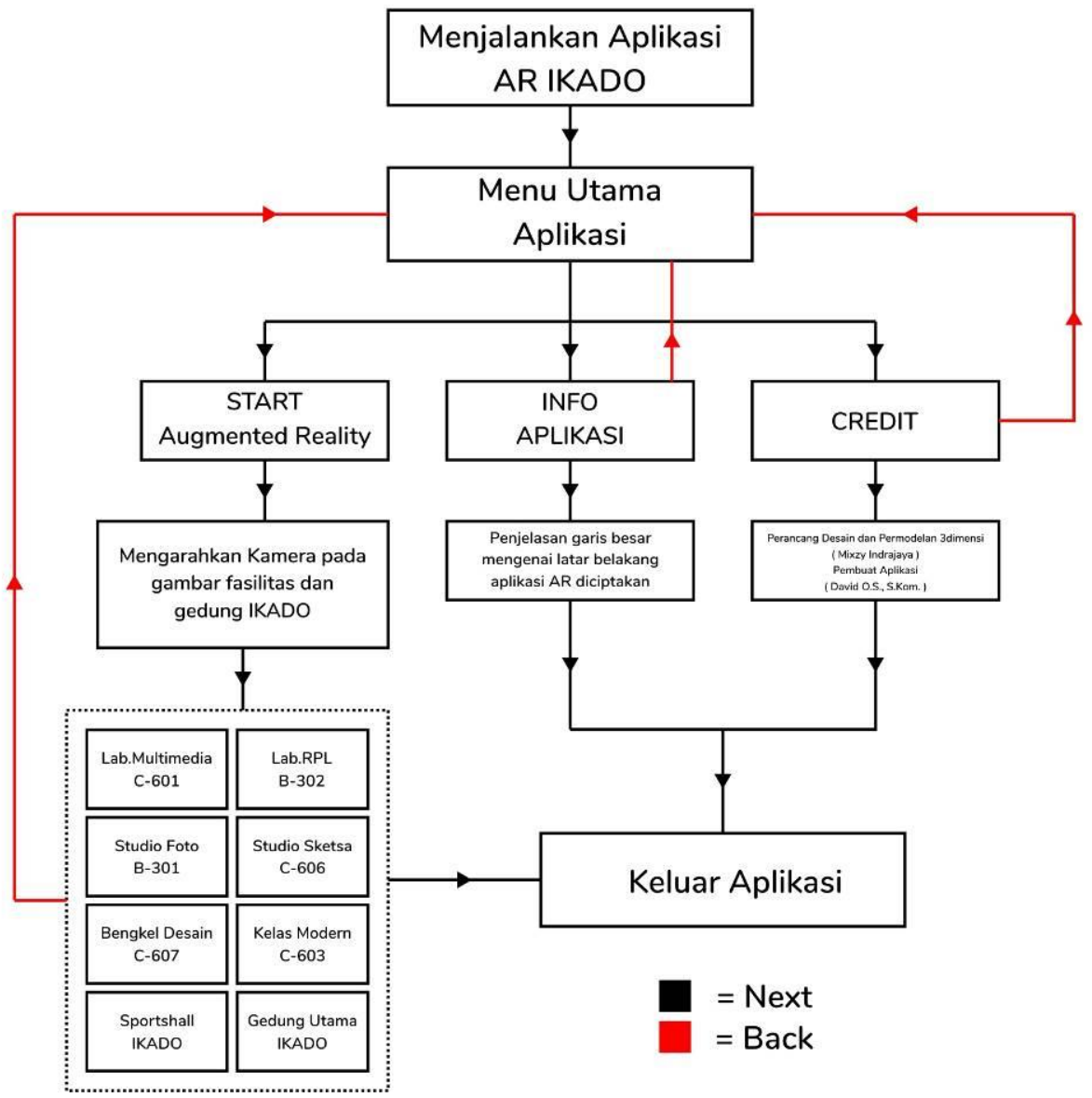

Gambar 9. Alur Pengoperasian

Sumber: Penulis

\section{SIMPULAN DAN SARAN}

\section{Simpulan}

Dalam merancang new media ini, dibutuhkan ketelitian dan kesabaran pada setiap prosesnya, karena perancangan model 3dimensi memerlukan detail yang baik agar dapat sesuai dengan keadaan nyata. Dalam perancangan new media ini, juga diperlukan gaya desain yang dapat menyesuaikan identitas dari IKADO sendiri, sehingga semua media dapat berkaitan satu sama lain.

Media utama dari perancangan ini adalah Augmented Reality berupa buku gedung dan fasilitas IKADO yang berisi gambar-gambar sebagai image target untuk model 3dimensi gedung dan fasilitas IKADO, penulis juga merancang aplikasi AR yang dapat memindai image target sehingga dapat memperlihatkan 
model 3dimensi gedung dan fasilitas IKADO, hal ini akan memudahkan calon mahasiswa dan orang tua untuk mendapatkan gambaran mengenai gedung dan fasilitas IKADO.

Selain itu, penulis juga merancang media pendukung dengan tujuan memperjelas informasi yang ada pada media utama seperti Virtual Reality dan Video 360derajat gedung dan fasilitas IKADO dan brosur yang berisikan image target dan QR code video 360 derajat, brosur ini ditujukan untuk para audiensi yang ingin mengakses media AR ketika tidak berada di area pameran Pendidikan.

\section{Saran}

Setelah melewati proses perancangan ini, disarankan kepada pihak lain yang akan melakukan perancangan dengan topik serupa untuk dapat memperhatikan spesifikasi komputer yang memadai, agar proses perancangan tidak terhambat, dikarenakan proses modelling 3D, teksturing, lighting dan rendering hingga resolusi $4 \mathrm{~K}$ membutuhkan performa komputer yang baik, untuk menghindari hambatan seperti force close, bluescreen dan sebagainya.

Selain itu diperlukan juga informasi terkait resolusi-resolusi yang didukung pada setiap gawai, pada jenis tertentu tidak dapat mendukung resolusi hingga $4 \mathrm{~K}$ (3840 piksel x 2160) sedangkan pada perangkat komputer dapat mendukung hingga resolusi $4 \mathrm{~K}$.

\section{DAFTAR PUSTAKA}

Barkah, Avief Muhammad dan Agustina, Rini. (2017). Pemanfaatan Augmented Reality sebagai media pembelajaran interaktif pengenalan candi-candi di malang raya berbasis mobile android. Malang: Universitas Kanjuruhan.

Lenurra, Ferry dan Pratiwi, Dian. (2017). Penerapan Teknologi Augmented Reality sebagai media promosi apartemen dengan metode markerless. Jakarta: Universitas Trisakti

Santoso, Didik. (2015). Rancang Bangun Aplikasi Augmented Reality untuk menampilkan proses pembuatan Batik Tulis. Surakarta: Universitas Muhammadiyah Surakarta.

Uyung Sulaksana. (2007). Integrated Marketing Communications. Jakarta: Pustaka Pelajar. 